\title{
Assessment of Aerosol Radiative Impact over Oceanic Regions Adjacent to Indian Subcontinent Using Multisatellite Analysis
}

\author{
S. K. Satheesh,, ${ }^{1,2}$ V. Vinoj, ${ }^{1,3}$ and K. Krishnamoorthy ${ }^{4}$ \\ ${ }^{1}$ Indian Institute of Science, Bangalore 560012, India \\ ${ }^{2}$ Divecha Centre for Climate Change, Indian Institute of Science, Bangalore 560012, India \\ ${ }^{3}$ Pacific Northwest National Laboratory, 902 Battelle Boulevard, Richland, WA 99352, USA \\ ${ }^{4}$ Space Physics Laboratory, Vikram Sarabhai Space Centre, Thiruvananthapuram 695022, India \\ Correspondence should be addressed to S. K. Satheesh, profsks@gmail.com
}

Received 5 April 2010; Revised 28 July 2010; Accepted 27 August 2010

Academic Editor: Vito Vitale

Copyright (๑) 2010 S. K. Satheesh et al. This is an open access article distributed under the Creative Commons Attribution License, which permits unrestricted use, distribution, and reproduction in any medium, provided the original work is properly cited.

Using data from Ozone Monitoring Instrument (OMI) and Moderate Resolution Imaging Spectroradiometer (MODIS) instruments, we have retrieved regional distribution of aerosol column single scattering albedo (parameter indicative of the relative dominance of aerosol absorption and scattering effects), a most important, but least understood aerosol property in assessing its climate impact. Consequently we provide improved assessment of short wave aerosol radiative forcing (ARF) (on both regional and seasonal scales) estimates over this region. Large gradients in north-south ARF were observed as a consequence of gradients in single scattering albedo as well as aerosol optical depth. The highest ARF $\left(-37 \mathrm{~W} \mathrm{~m}^{-2}\right.$ at the surface) was observed over the northern Arabian Sea during June to August period (JJA). In general, ARF was higher over northern Bay of Bengal (NBoB) during winter and premonsoon period, whereas the ARF was higher over northern Arabian Sea (NAS) during the monsoon and postmonsoon period. The largest forcing observed over NAS during JJA is the consequence of large amounts of desert dust transported from the west Asian dust sources. High as well as seasonally invariant aerosol single scattering albedos $(\sim 0.98)$ were observed over the southern Indian Ocean region far from continents. The ARF estimates based on direct measurements made at a remote island location, Minicoy $\left(8.3^{\circ} \mathrm{N}, 73^{\circ} \mathrm{E}\right)$ in the southern Arabian Sea are in good agreement with the estimates made following multisatellite analysis.

\section{Introduction}

The estimation of regional average aerosol radiative effect requires accurate information on the spatial pattern of aerosol optical depth (AOD) as well as aerosol single scattering albedo (SSA) [1]. The aerosol optical depth measurements using MODIS instrument over oceans have been found to be quite accurate $[2,3]$. This has been confirmed based on several ship-based and island-based Sun photometer observations. A detailed knowledge of SSA, which is the fraction of intercepted radiation that is scattered, is one of the largest uncertainties in climate forcing assessments [4]. Depending on the surface albedo and vertical distribution of aerosols, a change (decrease) in single scattering albedo from 0.9 to 0.8 can even change the sign of forcing from negative to positive [5]. The modeling of aerosol absorption is largely dependant on aerosol chemical composition, size distribution, and morphology which are highly uncertain especially over Asian regions. The carbonaceous aerosol compounds like black carbon emitted from both biomass and fossil fuel burning are some of the major uncertainty in the understanding of aerosol absorption [610]. Therefore, continuous measurements of single scattering albedo on a global basis could significantly reduce these uncertainties which hamper estimation of their radiative and hence climate effects. Till recently the spatial pattern of aerosol single scattering albedo was not available on the spatial scale required for climate model assimilation. The recent retrieval of aerosol absorption optical depth from OMI has made estimation of spatial pattern of aerosol SSA and hence radiative forcing possible. However, the accuracy of single scattering albedo derived by OMI depends on 
the assumptions involved such as aerosol layer height [11]. Thus, there exists large uncertainty in these retrievals that impact the direct estimation of single scattering albedo. Therefore, estimation of aerosol radiative effect over the oceans using the single scattering albedo retrieved from OMI may be uncertain. Recently, Satheesh et al. [12] proposed a joint OMI-MODIS retrieval technique to make improved assessment of aerosol absorption. In this paper, we have retrieved regional distribution of aerosol single scattering albedo using OMI-MODIS joint retrieval following Satheesh et al. [12] over the oceanic regions adjacent to Indian subcontinent. Consequently, we provide improved assessment of short wave aerosol radiative forcing (ARF) (on both regional and seasonal scales) estimates over this region by utilizing the aerosol optical depth from MODIS and SSA from joint OMIMODIS retrieval technique in conjunction with a radiative transfer model. The spatial pattern of aerosol absorption over oceans adjacent to Indian subcontinent and consequent radiative impact are discussed.

\section{Data and Methodology}

Earlier studies have shown that the MODIS-derived aerosol optical depth is quite accurate over oceans $[2,3]$. The validation of MODIS aerosol optical depth over oceanic regions around India has been carried out using AOD measurements from ship-based and island-based measurements $[13,14]$. The MODIS ocean algorithm makes use of its fine spatial resolution observations and wide spectral range to mask out suspended river sediments, clouds, and Sun-glint, then inverts the radiance at several wavelengths (550 to $2130 \mathrm{~nm}$ ) to retrieve spectral aerosol optical depth $(\mathrm{AOD})$ and particle size information $[15,16]$. The broad spectral range from $0.55 \mu \mathrm{m}$ to $2.13 \mu \mathrm{m}$ provides sufficient information to retrieve the accurate spectral signature of the aerosol. The MODIS ocean aerosol retrieval is documented fully in the literature, [16-18] and hence is not repeated here.

The OMI near UV aerosol algorithm (OMAERUV) uses measurements made at two wavelengths in the UV region (354 and $388 \mathrm{~nm}$ ). The large sensitivity of the upwelling radiances to aerosol absorption in this spectral region [19] is used to retrieve the aerosol absorption. The OMAERUV aerosol products are UV Aerosol Index (AI), and aerosol extinction and absorption optical depths at $388 \mathrm{~nm}$. Aerosol extinction optical depth (AOD) and aerosol absorption optical depth (AAOD) at $388 \mathrm{~nm}$ are derived using an inversion algorithm that uses precomputed reflectance for a set of assumed aerosol models. Three major aerosol types are considered: desert dust, carbonaceous aerosols associated with biomass burning, and weakly absorbing sulfate-based aerosols. Each of these aerosol types are represented by seven aerosol models of varying single scattering albedo, for a total of twenty-one microphysical models. Given the large size $\left(13 \times 24 \mathrm{~km}^{2}\right.$ at nadir $)$ of the OMI pixels, subpixel cloud contamination is one of the challenging issues resulting in the overestimation of the extinction optical depth and underestimation of the single scattering coalbedo in OMI [19]. However, in the calculation of the absorption optical depth a cancellation of errors takes place that allows the
AAOD retrieval even in the presence of small amounts of cloud contamination. Detailed description of the algorithm is given in an overview paper by Torres et al. [11].

The Aura-OMI and the Aqua-MODIS instruments fly on A-train platforms within 8 minutes of each other. The quasisimultaneity of their observations makes these sensors suitable for the application of a combined retrieval approach. OMI retrieves both aerosol extinction optical depth (AOD) and absorption information reported as single scattering albedo, while MODIS retrieves AOD and particle size [11, 18]. The OMI-retrieved information on absorbing aerosols depends on the assumed aerosol layer height. The MODIS retrieval algorithm, on the other hand, is insensitive to the aerosol vertical distribution but it needs to assume a value of the single scattering albedo (in the form of aerosol models). OMI pixels at a spatial resolution of $13 \mathrm{~km}$ by $24 \mathrm{~km}$ are often cloud contaminated (owing to large pixel size) whereas MODIS pixels at a resolution of $500 \mathrm{~m}$ are significantly less affected by cloud contamination. Thus the combination of the observations from the two sensors offers the opportunity of taking advantage of their individual strengths: OMI's unique sensitivity to aerosol absorption and MODIS accurate retrievals of aerosol optical depth (see [12] for details). Please note that even though MODIS radiances (Level-1) are available at $500 \mathrm{~m}$ resolution for cloud screening, aerosol products are available only at $10 \mathrm{~km}$ resolution (Level-2 data).

MODIS's strength is the availability of several channels in the visible through short wave infrared bands that permit accurate retrieval of AOD across a wide spectral range, especially over ocean. OMI's strength is its sensitivity to aerosol absorption in the near UV. However, the accuracy of OMI's retrieval is limited by the fact that the standard aerosol algorithm is sensitive to assumptions of aerosol height, whereas, MODIS derived AOD is not sensitive to aerosol layer height. A joint OMI-MODIS methodology was recently proposed by Satheesh et al. [12] by utilizing the respective strengths of MODIS and OMI to derive aerosol absorption with a greater accuracy, which we follow in this study to obtain information on the regional distribution of aerosol absorption.

2.1. OMI-MODIS Algorithm in Brief. The approach used in this work consists on using the MODIS retrieved AOD as input to the OMI retrieval. A difficulty in this method is the need to extrapolate the MODIS-retrieved AOD (at visible wavelengths) to the near UV $(388 \mathrm{~nm})$ where OMI requires the AOD information for its retrieval. Satheesh et al. [12] have tested MODIS' ability to estimate AOD in the UV, by comparing the estimated UV AOD with high quality ground-based observations [Aerosol Robotics Network (AERONET)]. They demonstrated that it is possible to improve the linear extrapolation into the UV by including information on the AOD spectral curvature. The success of using the MODIS visible and near IR spectral AODs to estimate UV optical depth suggests that we can use MODISpredicted AOD in the UV to constrain the OMI inversion, and leave OMI free to return information on aerosol height and most importantly, aerosol absorption. By utilizing this 


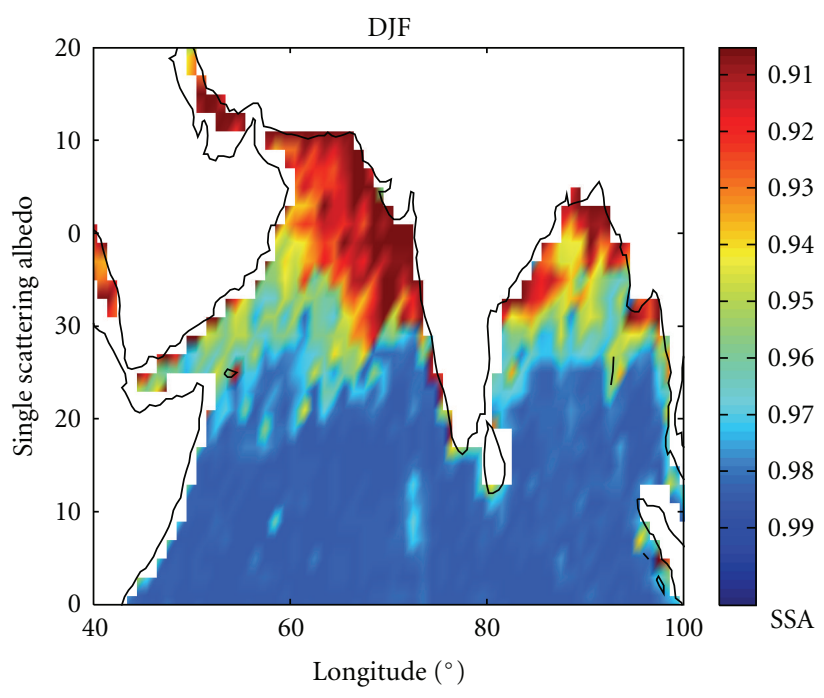

(a)

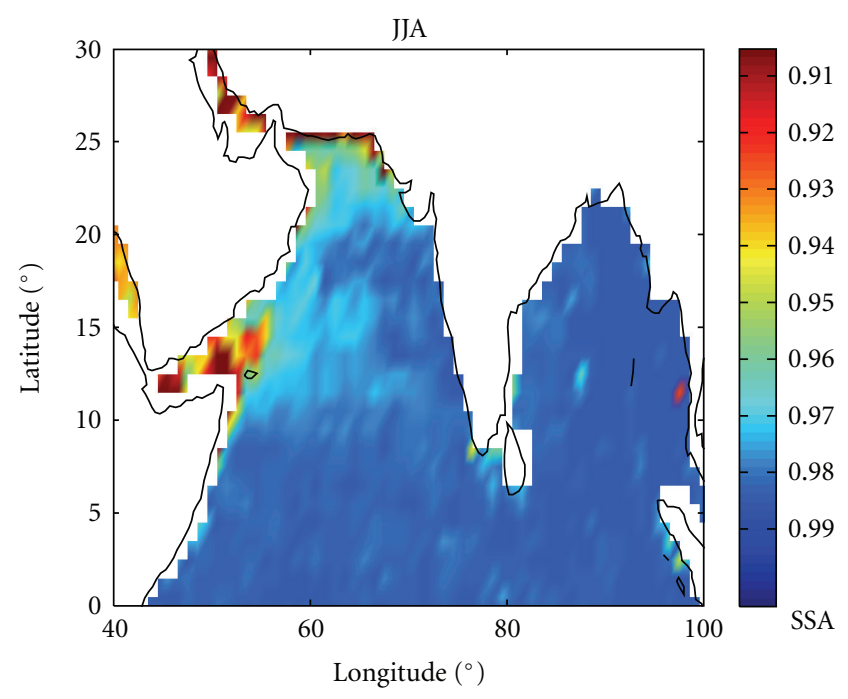

(c)

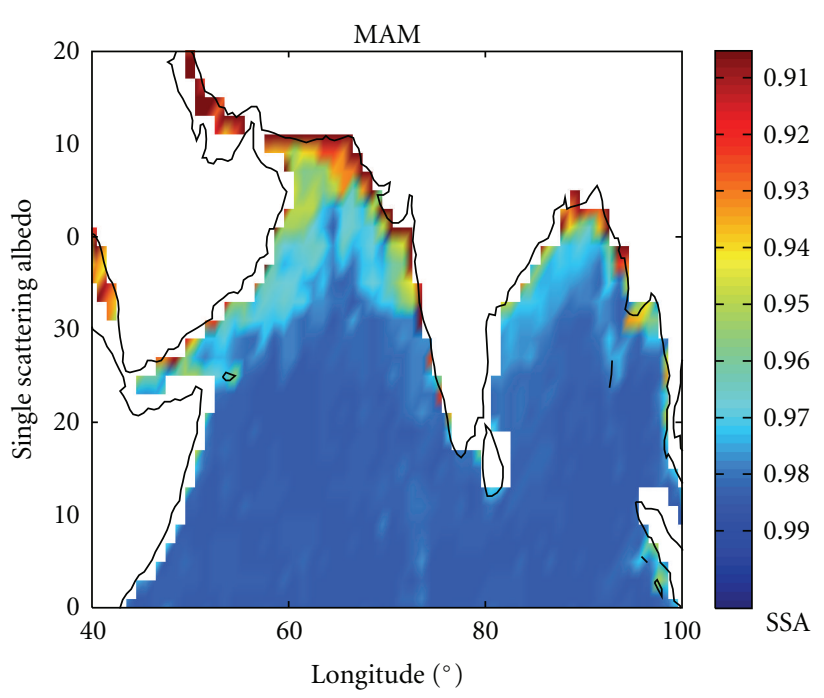

(b)

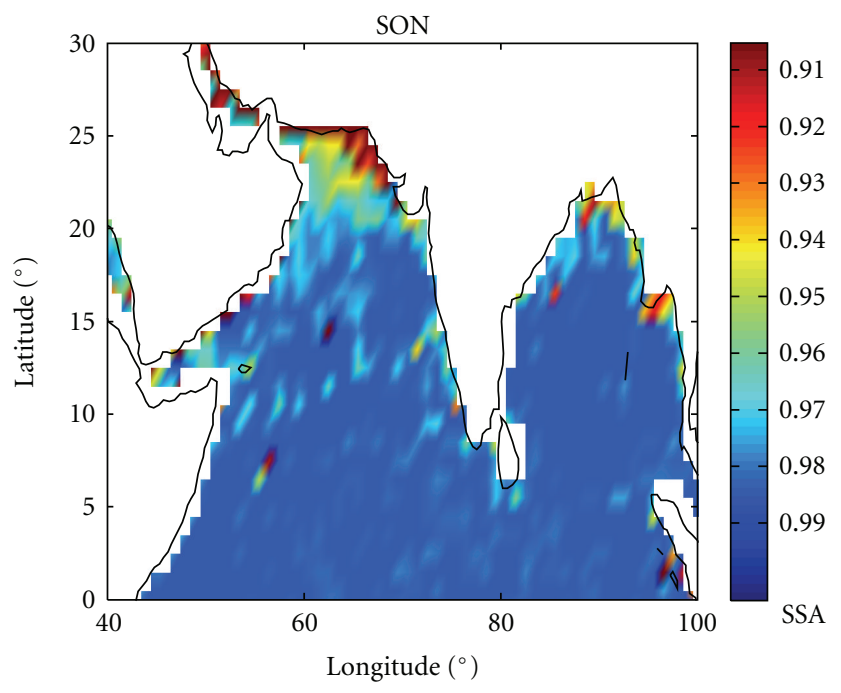

(d)

FIGURE 1: Seasonal and spatial distribution of aerosol single scattering albedo determined using the joint OMI/MODIS methodology.

observation, Satheesh et al. [12] followed a hybrid approach involving OMI and MODIS data in which MODIS can constrain the OMI retrieval by providing the AOD at $0.38 \mu \mathrm{m}$. Thus, joint OMI-MODIS retrieval can provide improved estimate of aerosol single scattering albedo. More details of this approach are available in Satheesh et al. [12] and hence are not repeated here.

\section{Results and Discussion}

3.1. Single Scattering Albedo. The regional distribution of aerosol single scattering albedo (SSA) derived using the joint OMI-MODIS methodology is shown in Figure 1. We find large spatial variation in SSA indicating a largely differing aerosol composition. We observe that the values of SSA over the vast open oceans are close to $\sim 0.98$ which signifies largely scattering nature of aerosols possibly due to the dominance of sea-salt aerosols. Close to the continents, the values are as low as $\sim 0.88$ to 0.91 signifying moderately absorbing nature of the aerosols indicating the effect of anthropogenic black carbon. Such low values of SSA $(\sim 0.9)$ were reported during Indian Ocean Experiment (INDOEX) over north Indian Ocean based on measurements carried out over an island location [10]. Lowest SSA (highest absorption) was observed in the northern Arabian Sea $(\sim 0.87)$ during the winter (December-January-February). We find that the north-south gradient in SSA is largest during winter over the Arabian Sea as well as over the Bay of Bengal (Figure 2). It can be seen that during all the seasons, there exist a north-south gradient with higher SSA over the open oceans and decreasing as we move northwards (Figure 2). While comparing various SSA values reported in the past, it may be noted that the SSA reported here from satellite measurements is representative of the atmospheric column. 


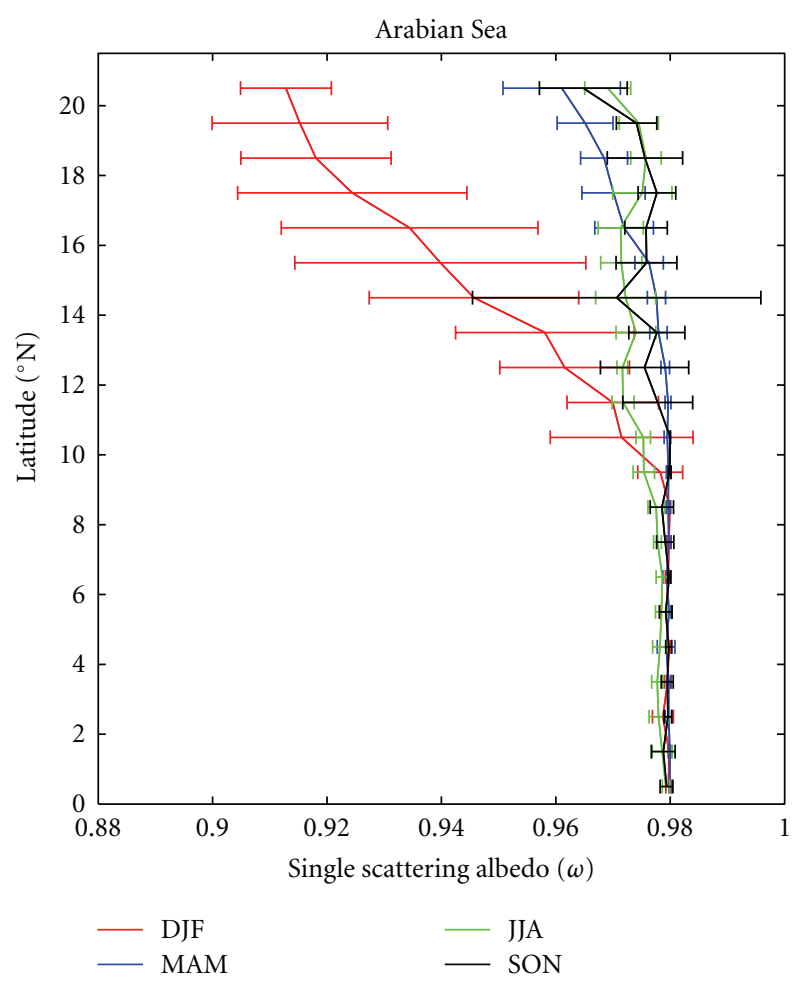

(a)

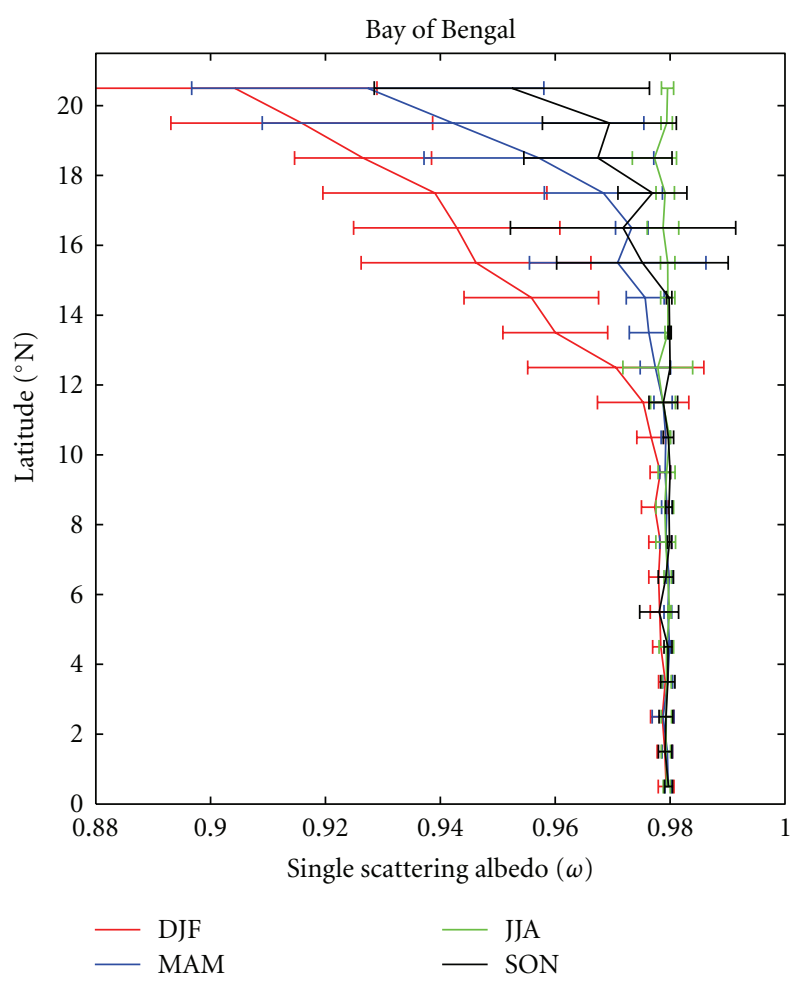

(b)

FIgURE 2: Latitudinal gradient of single scattering albedo over Arabian Sea and Bay of Bengal.

An SSA value of 0.89 to 0.93 at the mid-visible was inferred from airborne measurements during Tropospheric Aerosol Radiative Forcing Observational Experiment (TARFOX) in July 1996 over the eastern US and western Atlantic Ocean [20, 21]. Dubovik et al. [22] retrieved SSA from measurements made during Smoke Clouds and RadiationBrazil (SCAR-B) campaign in August and September 1995 and found a value of 0.87 at $670 \mathrm{~nm}$. The SSA retrieved from pyrheliometers and pyranometers in northern China during the period between 1993 and 2001 ranged from 0.80 to 0.85 at $550 \mathrm{~nm}$ [23] However SSA from Qiu et al. [23] is most likely underestimated when compared with several later studies [24, 25]. Ganguly et al. [26] reported a value of $\sim 0.7$ to 0.9 from a land-based campaign over the central part of India. But most of the low values of SSA reported are regions of high pollution or biomass burning. The lower value of SSA observed over the Indian region during winter as shown by Ganguly et al. [26] could be explained by seasonal biomass burning [27-29] and dust particles transported from Sahara (Figure 3 shows the prevailing wind pattern). In the present study, SSA retrievals were restricted to oceanic regions only due to the uncertainties involved in the retrieval of AOD from MODIS over land.

3.2. Aerosol Optical Depth. The seasonal and spatial pattern of aerosol optical depth from MODIS is shown in Figures 4 and 5. There are some important observations in the spatial patterns of aerosol optical depth. (a) High AODs close to the coast and a sharp gradient over the ocean. (b) Strong north-south gradient. (c) Detached highs in the AODs over the ocean. (d) The highest AODs over both Arabian Sea and Bay of Bengal are observed during summer and the lowest during winter.

There have been several cruise-based measurements to understand the aerosol characteristics over the Arabian Sea, but most of them were either season or region specific. Though addressing important and specific scientific questions, they are not capable of providing the unprecedented spatial and temporal resolution that satellite observations offer. By integrating several independent island and shipborne measurements Satheesh et al. [30] showed that there exists a latitudinal gradient in AODs over the Arabian Sea up to about $12^{\circ} \mathrm{N}$. The gradient observed during the summer (JJA) continues almost exponentially $\left(\sim 0.2\right.$ at $2^{\circ} \mathrm{N}$ to $\sim 0.8$ at $20^{\circ} \mathrm{N}$ ) unlike that during other seasons when gradient becomes shallower. The JJA season is characterized by heavy winds associated with south-west monsoon which leads to large production of sea-salt aerosols over the Arabian Sea. In spite of this fact, the AOD is decreasing towards the south indicating the dominating strength of desert dust from west Asia.

There were only a few aerosol measurements over northern AS during JJA due to the hostile weather conditions as well as persistent cloudiness [14] [13]. Ship-borne measurements have shown AOD of 0.4 to 0.7 over northern Arabian Sea [14]. The largest seasonality in AOD was observed over northern Arabian Sea, whereas their latitudinal gradient was similar during winter and pre-monsoon period (Figure 5). 


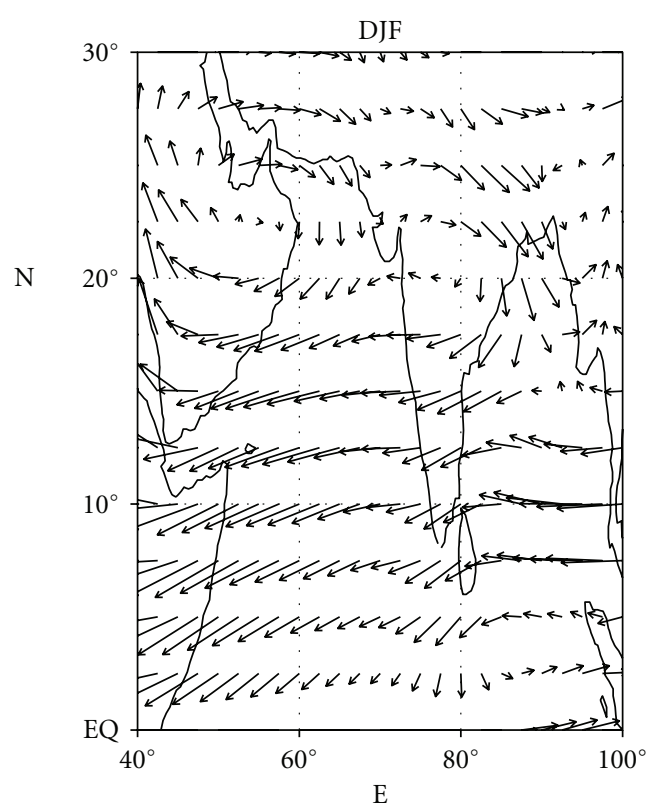

(a)

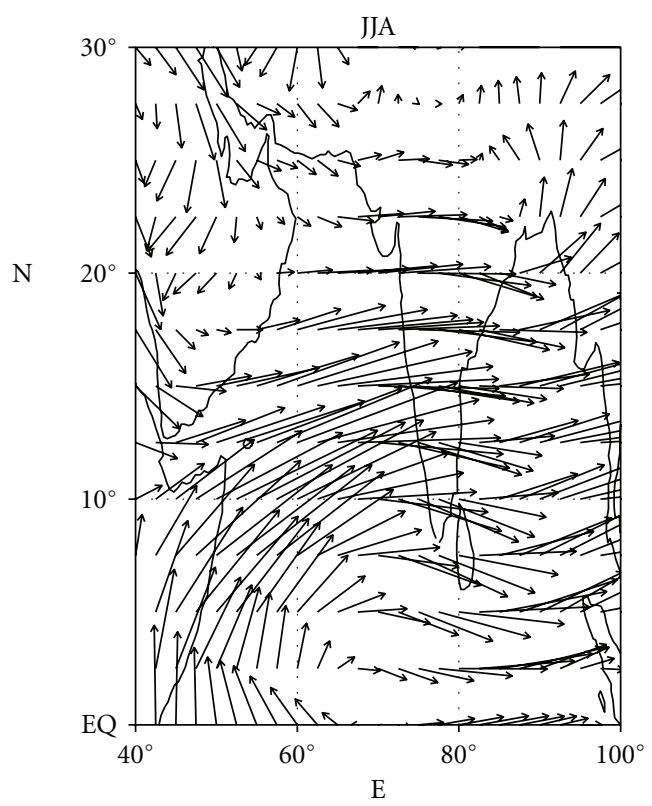

(c)

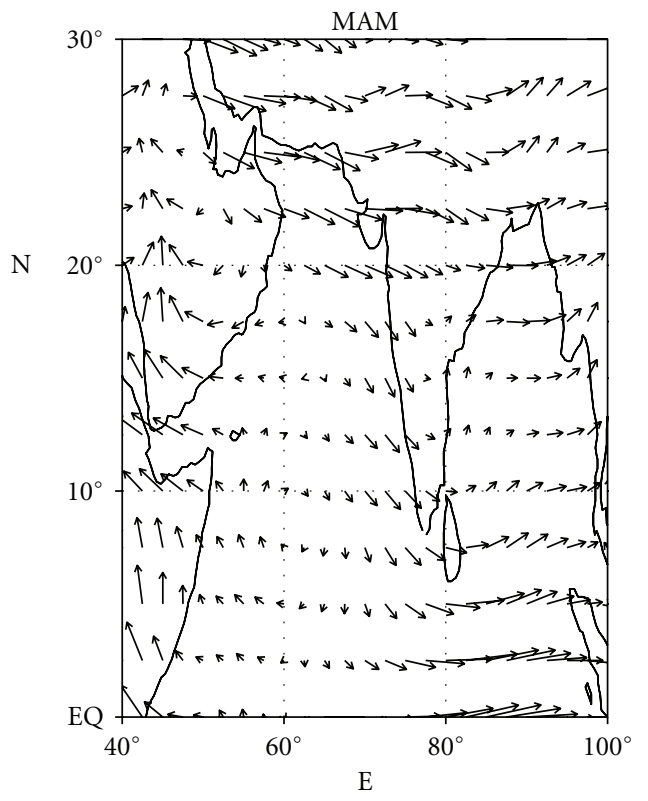

(b)

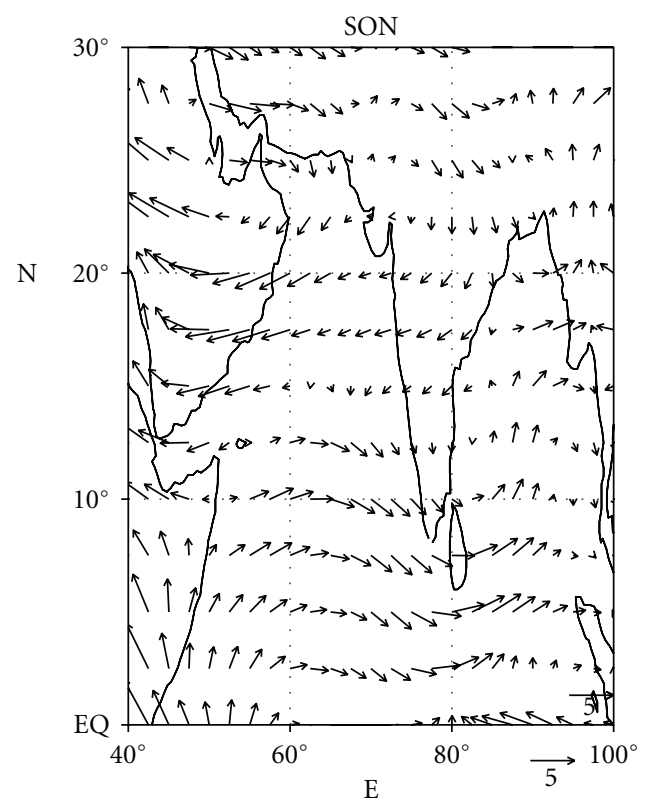

(d)

FIGURE 3: Observed wind pattern over the Indian region during different seasons (using NCEP Reanalysis).

Over the BoB, the highest AODs are more confined to the north $\mathrm{BoB}$ and close to the east coast of India. Therefore, there exists a large north-south latitudinal gradient, also a gradient over the east coast of India as well as the south coast of Bangladesh and west coast of Myanmar. Due to the land locked nature of $\mathrm{BoB}$ and its proximity to highly polluted regions, the AOD's are modulated by industrial pollution from various regions such as northern part of India and Bangladesh. Additional influence is the result of anthropogenic as well as natural biomass burning aerosols both from the northern part of India and the west coast of Myanmar (Nair et al., [31]). This makes BoB highly dynamic as far as changes in aerosol properties are concerned. Similar to the AS, the largest gradient over the BoB is also observed during JJA. But the gradients are shallower during all seasons except during JJA. Recent measurements over BoB have shown that the head $\mathrm{BoB}$ is dominated by the biomass burning aerosols transported from over Myanmar, whereas the southern BoB is more or less dominated by fossil fuel burning transported from the east coast of India (Nair et al., [31]). 


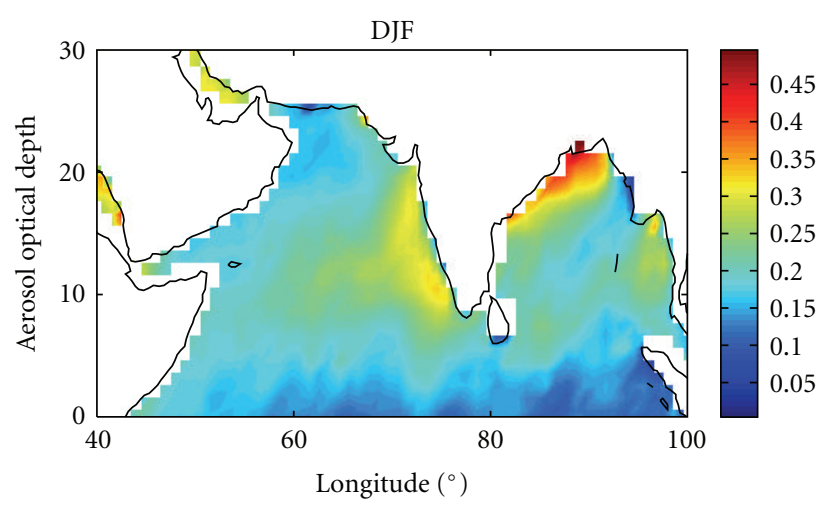

(a)

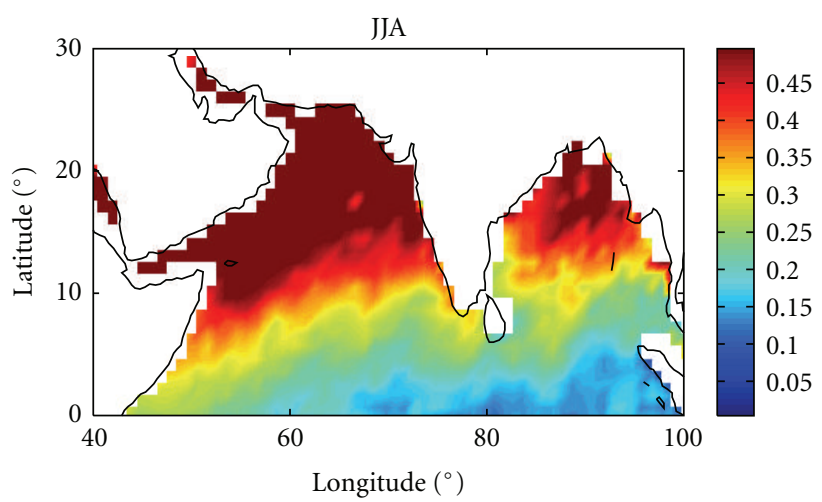

(c)

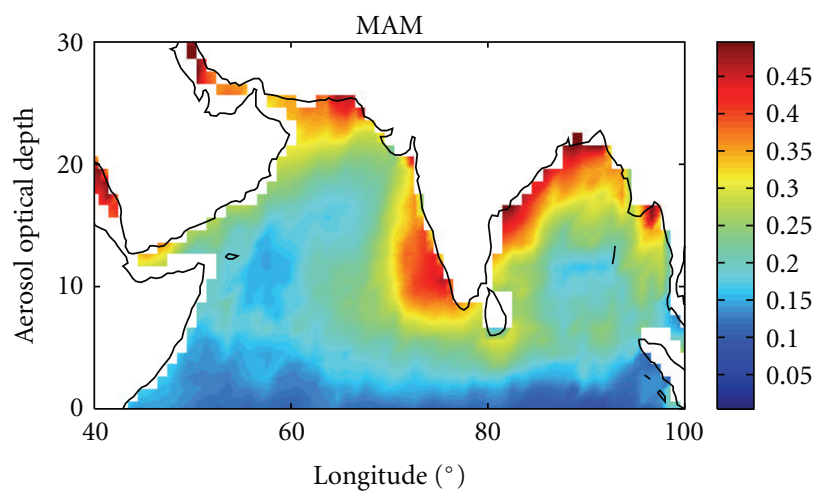

(b)

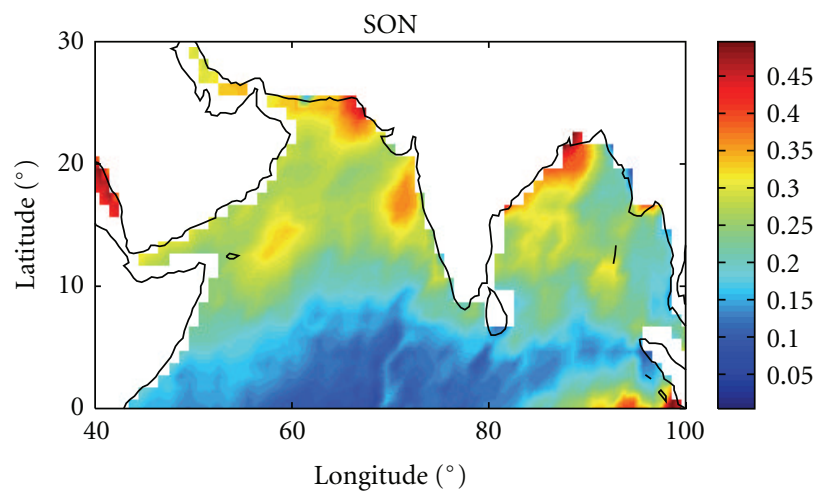

(d)

Figure 4: Seasonal and spatial distribution of aerosol optical depth over the oceanic regions around India.

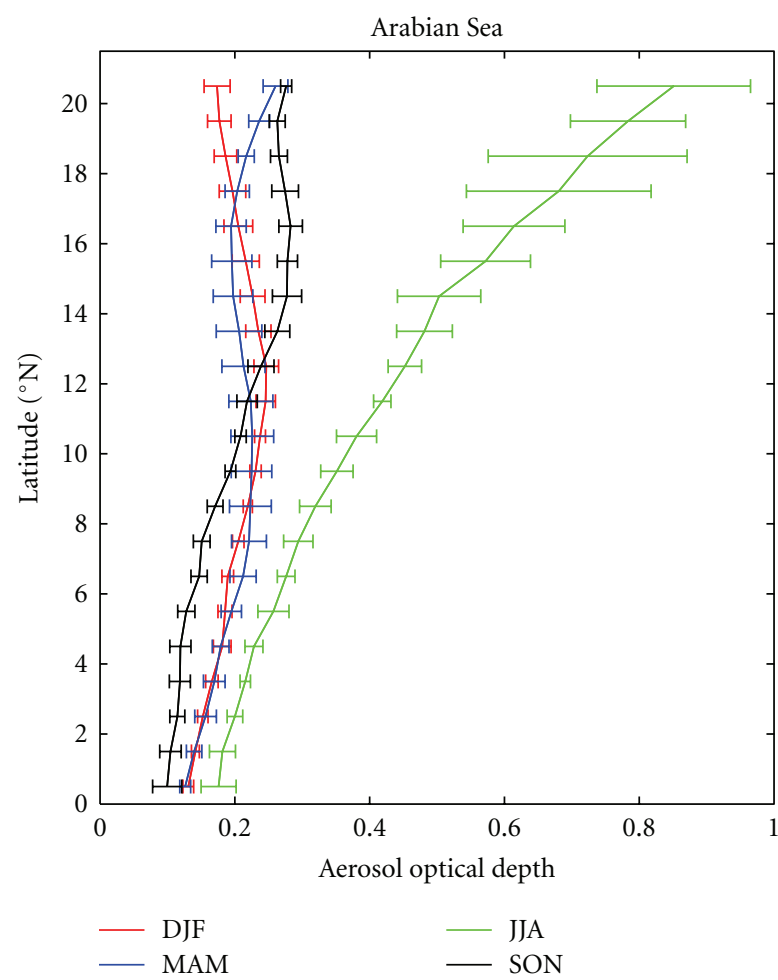

(a)

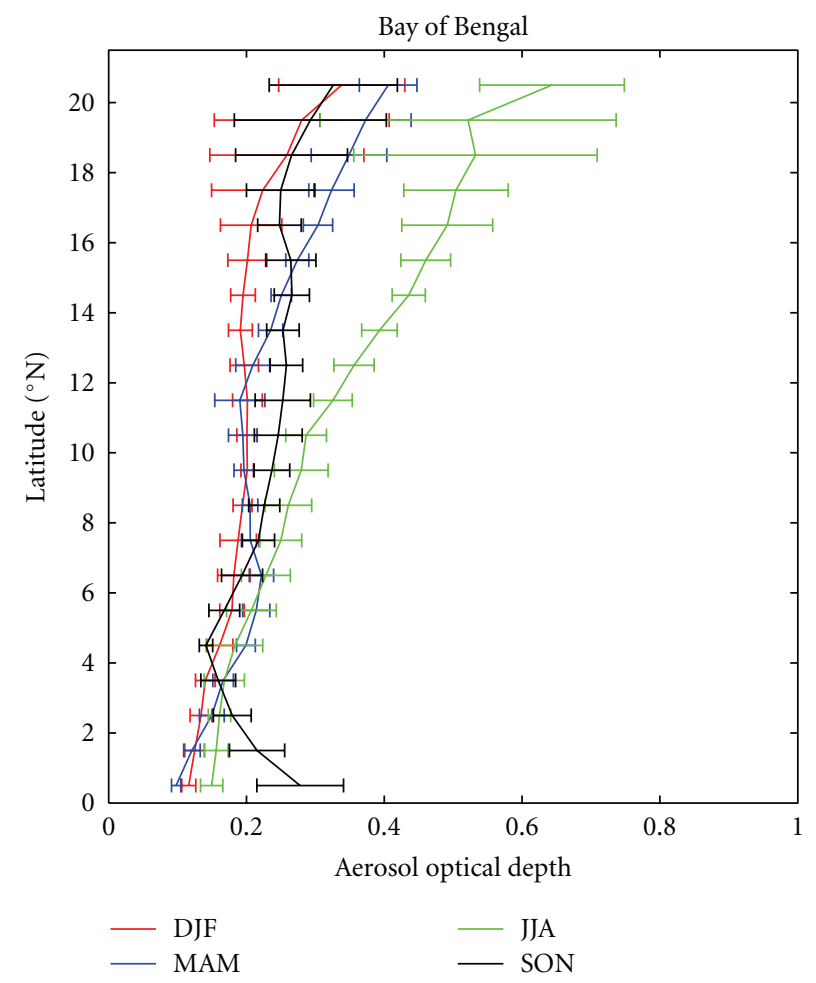

(b)

FIGURE 5: Latitudinal gradient of aerosol optical depth over Arabian Sea and Bay of Bengal. 


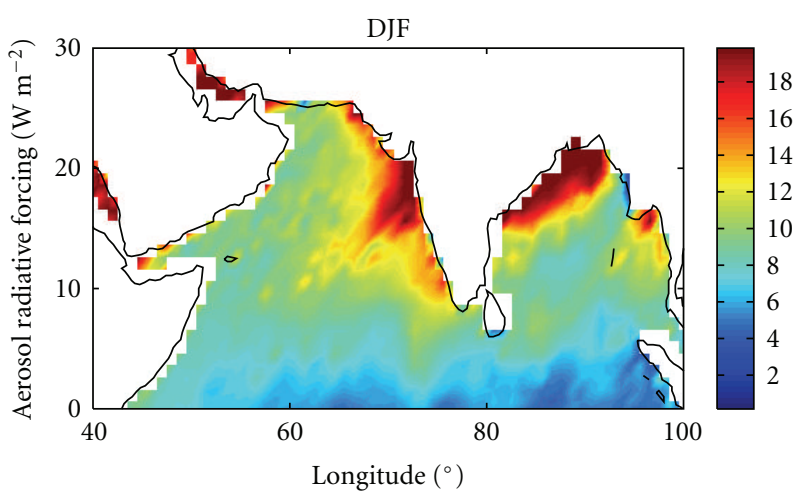

(a)

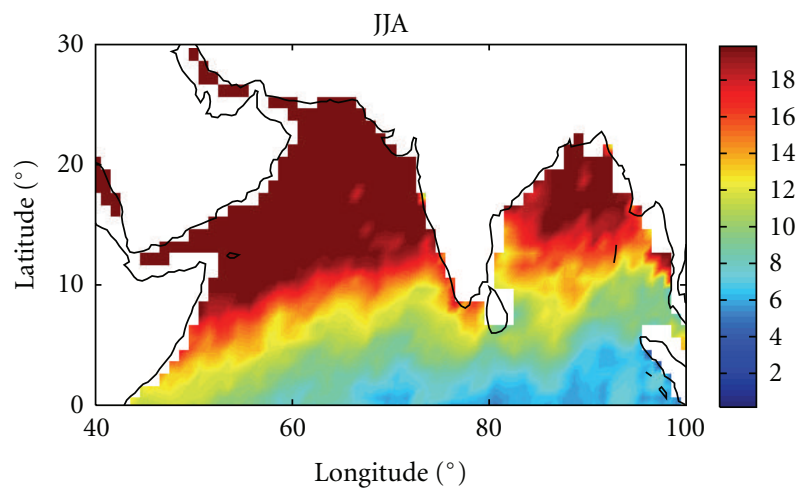

(c)

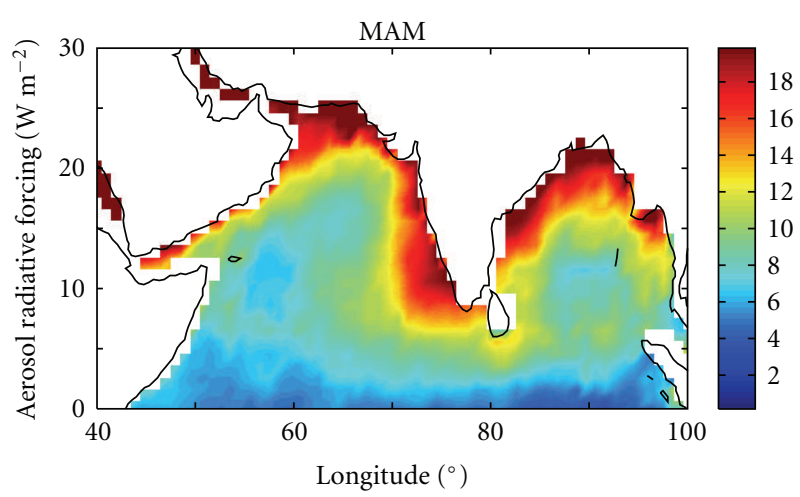

(b)

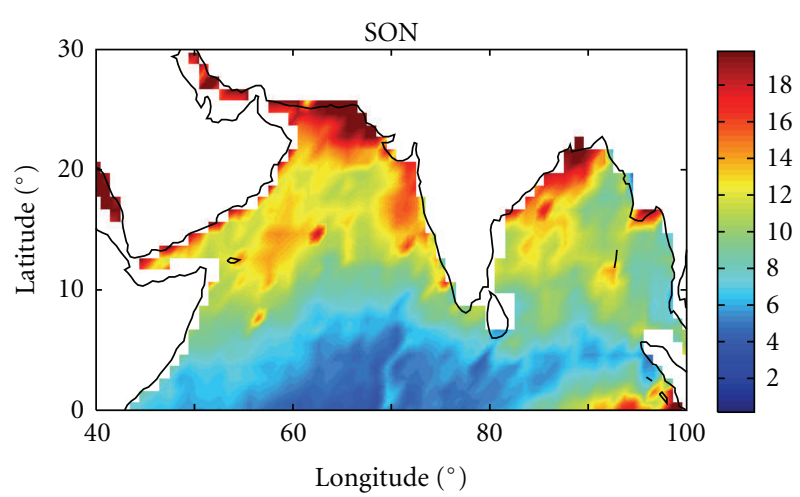

(d)

FIGURE 6: Seasonal and spatial distribution of surface aerosol radiative forcing over oceanic regions around India.

The large gradient in AOD (Figures 4 and 5) observed close to the coast can lead to large changes in the surface cooling within a very short distance (discussed in the next section). In Figure 4, the patterns shown are based on average AODs over each grid point over a three-month period and hence show the mean pattern during this period. As such, these features can be considered to be the average spatial pattern observed during the season irrespective of the day-to-day variations. Therefore, it is possible that such persistent north-south gradient in AOD can have large effect on the surface heat budget and hence change weather and climate regionally. In the present study, our main focus is to understand the spatial pattern of aerosol radiative impact, which is discussed in detail in the later sections. In the gradient pattern shown in Figure 5, the slight increase in AOD close to the equator over Bay of Bengal is due to the effect of aerosols from the Indonesian region during the postmonsoon period. The retrieved SSA using the joint OMIMODIS methodology and AOD from MODIS were used to determine the aerosol radiative effect at surface as well as TOA.

\subsection{Regional Distribution of Aerosol Radiative Impact. For} estimating the regional distribution of aerosol radiative impact, we have used the values (maps) of SSA along with aerosol spectral optical depth as input to a Discrete Ordinate
Radiative Transfer model [Santa Barbara DISORT Atmospheric Radiative Transfer (SBDART) model] to estimate the short-wave clear sky aerosol radiative forcing at the surface and top of the atmosphere (TOA). This model is designed and developed by University of California, Santa Barbara [32] and is based on a collection of well-tested and reliable physical models, which were developed by the atmospheric science community over the past few decades. We have used tropical atmosphere model to describe atmospheric profiles and zenith angle-dependent ocean albedo [32]. Ocean albedo for overhead Sun was around 6\%. We used eight streams in the radiative transfer calculation and computations were made for solar zenith angles at every $5^{\circ}$ and thus estimated diurnally averaged radiative forcing. Radiation model requires aerosol scattering phase function as well in addition to the spectral optical depth and single scattering albedo. Since OMI-MODIS approach does not provide information about aerosol scattering phase function (and hence asymmetry factor), we used the "maritime tropical" model of Hess et al. [33]. It may be noted that radiative forcing maps we report in this paper corresponds to diurnally averaged values.

The seasonal and spatial pattern of aerosol radiative forcing at the Earth's surface is shown in Figure 6. On a seasonal scale, the largest forcing at the surface was observed over the Arabian Sea during JJA (as large as $-37 \mathrm{~W} \mathrm{~m}^{-2}$ ). 


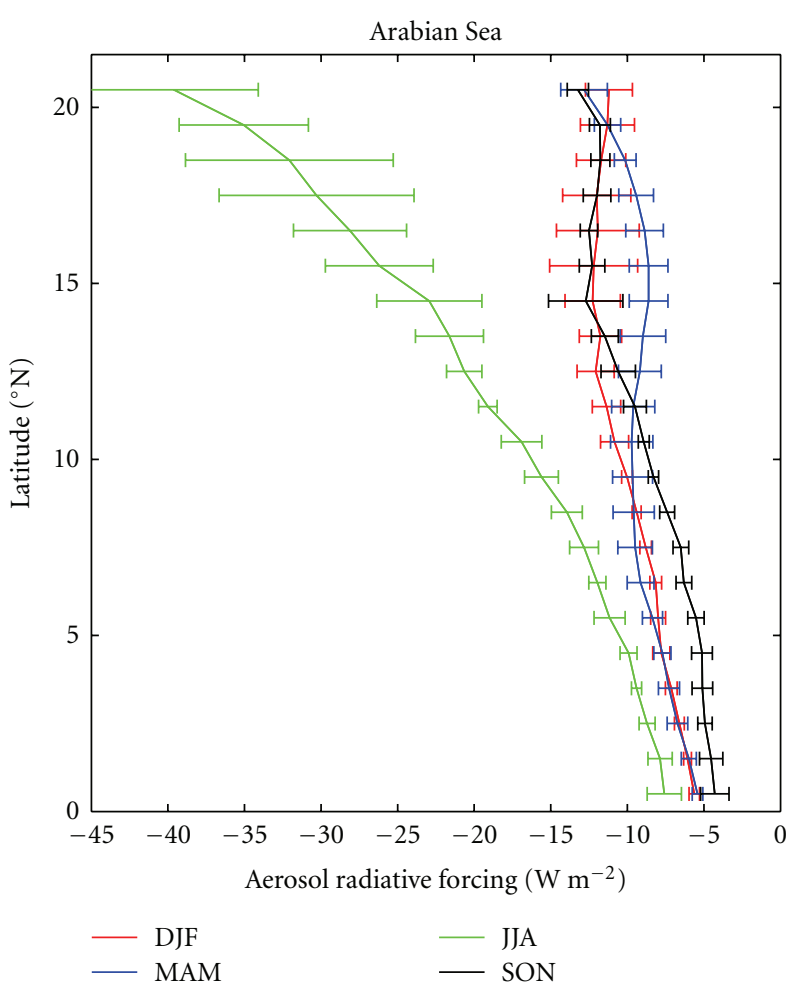

(a)

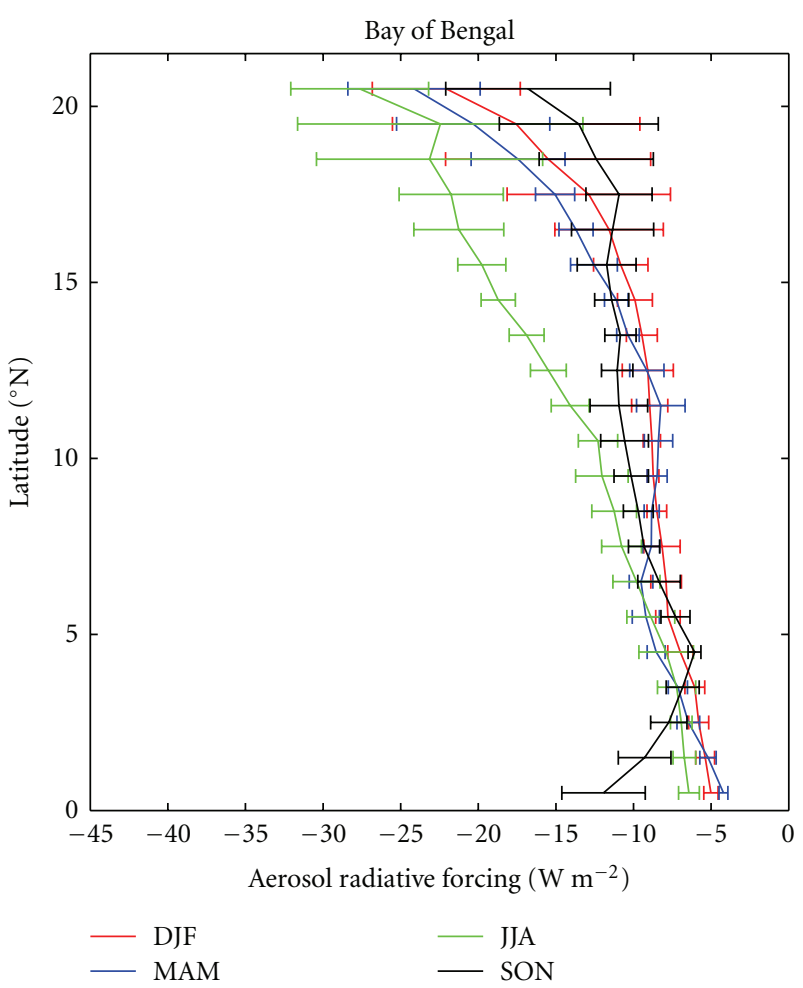

(b)

FIgURE 7: Latitudinal gradient of surface aerosol radiative forcing over Arabian Sea and Bay of Bengal.

In addition, a close examination of the gradient reveals that the gradient over Arabian Sea and Bay of Bengal at latitudes north of $15^{\circ} \mathrm{N}$ is weaker compared to that observed south of $15^{\circ} \mathrm{N}$ (Figures 7 and 8). Such observations have been reported for AOD earlier using measurements from several field campaigns (see [30]). The gradient of surface forcing during JJA is the largest with highest values of forcing is over the north of Arabian Sea (a six-fold increase compared to its value over southern Arabian Sea).

3.4. Average over Subregions. The large spatial as well as seasonal variation in aerosol radiative forcing (as a consequence of variability in aerosol properties like AOD and SSA over the Arabian Sea and Bay of Bengal) prompted us to look closer into this vast oceanic region by separating them into smaller subregions so as to understand the gradient and variability well. In this pursuit, we divided the whole oceanic regions around Indian subcontinent into 8 sub regions. They are North Arabian Sea (NAS, 15 to $25^{\circ} \mathrm{N}, 60$ to $70^{\circ} \mathrm{E}$ ), North Bay of Bengal (NBOB, 15 to $25^{\circ} \mathrm{N}, 85$ to $95^{\circ} \mathrm{E}$ ), Central Arabian Sea (CAS, 10 to $20^{\circ} \mathrm{N}, 57.5$ to $72.5^{\circ} \mathrm{E}$ ), Central Bay of Bengal (CBOB, 10 to $20^{\circ} \mathrm{N}, 82.5$ to $97.5^{\circ} \mathrm{E}$ ), Southern Arabian Sea (SAS) $\left(5\right.$ to $15^{\circ} \mathrm{N}, 60$ to $70^{\circ} \mathrm{E}$ ), Southern Bay of Bengal (SBOB, 5 to $15^{\circ} \mathrm{N}, 85$ to $95^{\circ} \mathrm{E}$ ), Northern part of Indian Ocean just south of the Indian subcontinent as North Indian Ocean (NIO, 0 to $5^{\circ} \mathrm{N}, 60$ to $95^{\circ} \mathrm{E}$ ), and the region just south of Equator as Equatorial Indian Ocean (EIO, $5^{\circ} \mathrm{S}$ to 0,60 to $95^{\circ} \mathrm{E}$ ). The boundaries of these regions are shown in Figure 9.
The mean AOD and SSA for each of the sub regions are shown in Figures 10 and 11. Important feature observed is the clear seasonality in both AOD and SSA over both Arabian Sea and Bay of Bengal, amplitude of which falls off as we move away from the land (i.e, moving towards south). In each of these figures, it can be observed that the seasonality and its amplitude are highest in the northern most subregions which are NAS and NBOB. NAS exhibits the largest AOD ( 0.77) during JJA which has already been discussed. The lowest SSA (0.92 to 0.97) in all of the sub regions except for the NIO and EIO regions is during DJF. This clearly points to the highly absorbing nature of the aerosols as a result of transport (due to prevailing winds, see Figure 3) of the emission over the land which is expected to have large fraction of absorbing (e.g., BC) aerosols as a result of pollution. One of the most striking features is that of the low amplitude or nearly seasonally invariant SSA $(\sim 0.98)$ for sub regions like NIO and EIO, clearly showing the low influence of absorbing aerosols over this region. The aerosols over these regions are therefore expected to be purely marine in nature. The lowest mean SSA for any region was observed for NAS during JJA (SSA 0.92). It may be noted that the SSA values discussed are values averaged for the sub regions; individual grid point SSA's as low as 0.88 were also observed over this region.

The mean aerosol radiative forcing at surface, TOA and atmosphere for each of the sub regions are shown in Figure 12. It can be seen that the highest aerosol radiative forcing is observed during JJA over NAS, which has been 


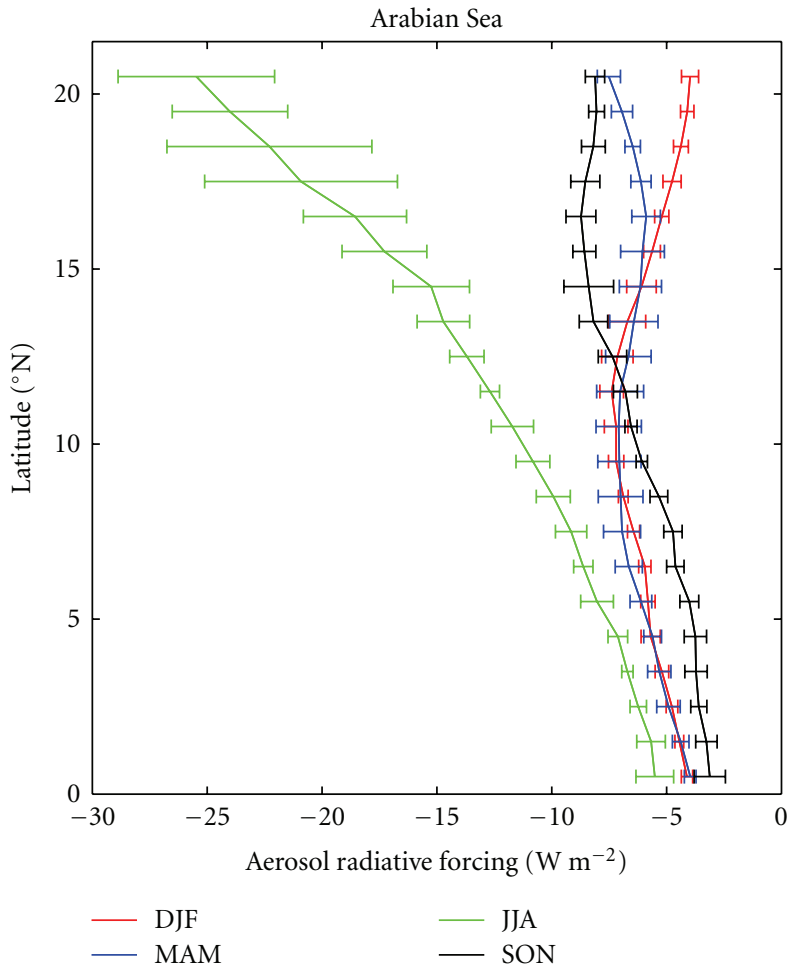

(a)

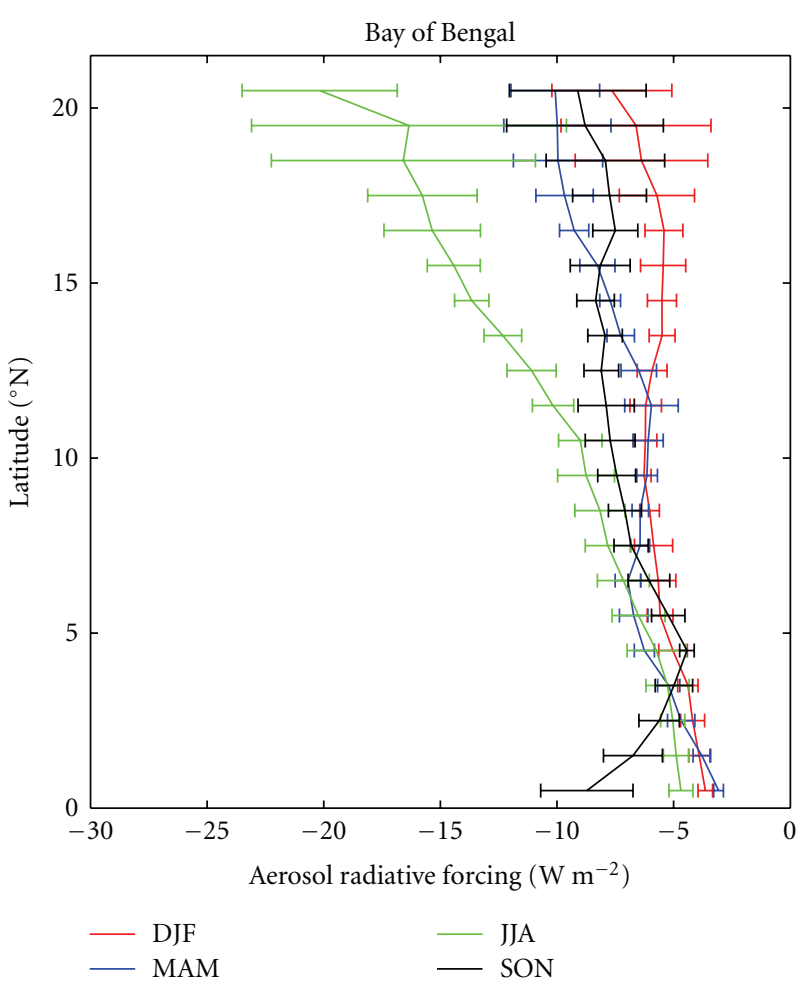

(b)

FIgURE 8: Latitudinal gradient of TOA aerosol radiative forcing over Arabian Sea and Bay of Bengal.

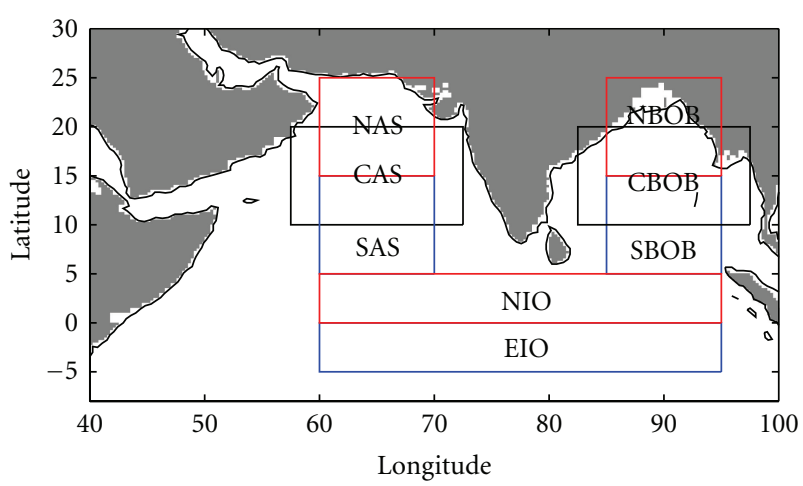

Figure 9: Details of the sub-regions selected over Arabian Sea, Bay of Bengal and North Indian Ocean.

shown as the region with the highest aerosol loading. The large transport of dust aerosols over to the northern Arabian Sea from the adjoining regions (NW India and West Asia) leads to this large forcing. Though $\mathrm{NBOB}$ also shows large forcing during JJA, it is much lower than the forcing estimated for NAS, which clearly shows the large impact of the dust transport. Previous investigations (or study) by Vinoj et al., [34] has shown that the forcing is maximum when the aerosol transport is from West Asia, the present result supplements those in situ findings made in southern Arabian Sea. It can be seen that the surface forcing in NAS are a factor of 6 to 7 more than that over SAS or NIO.
Moreover, the gradient in forcing (and consequent cooling) also is higher in Arabian Sea in comparison to BoB. Such large changes in surface forcing can have large effect on regional radiation budget and hence climate.

3.5. Comparison with Observations. The optical and microphysical properties of aerosols were measured at a remote island location, Minicoy, in the southern Arabian Sea from February 2006 to March 2007. Aerosol optical depth was measured using a multiwavelength radiometer, black carbon using aethalometer (Magee Scientific, USA) and aerosol size distribution using an optical particle counter (GRIMM Inc) (see [34], for details). Using observations made at Minicoy, Vinoj et al. [34] have estimated aerosol radiative forcing, which provided us an opportunity to validate our estimates made using OMI-MODIS joint retrieval. The aerosol radiative forcing estimated using observations made at Minicoy over a year during 2006 has been used as a validation for the present study. It can be seen (from Figure 13) that the forcing estimates made at Minicoy from observations and using the joint OMI-MODIS methodology are comparable. The only other such estimate available over this region is INDOEX forcing estimates carried out during 1999. It can be seen that INDOEX estimates are much higher than those reported in this study. One possible explanation is that INDOEX is representative of aerosols during winter over this region while our estimates are annually averaged and are more representative of the entire year. In addition, aerosols optical depth during INDOEX intensive field campaign 

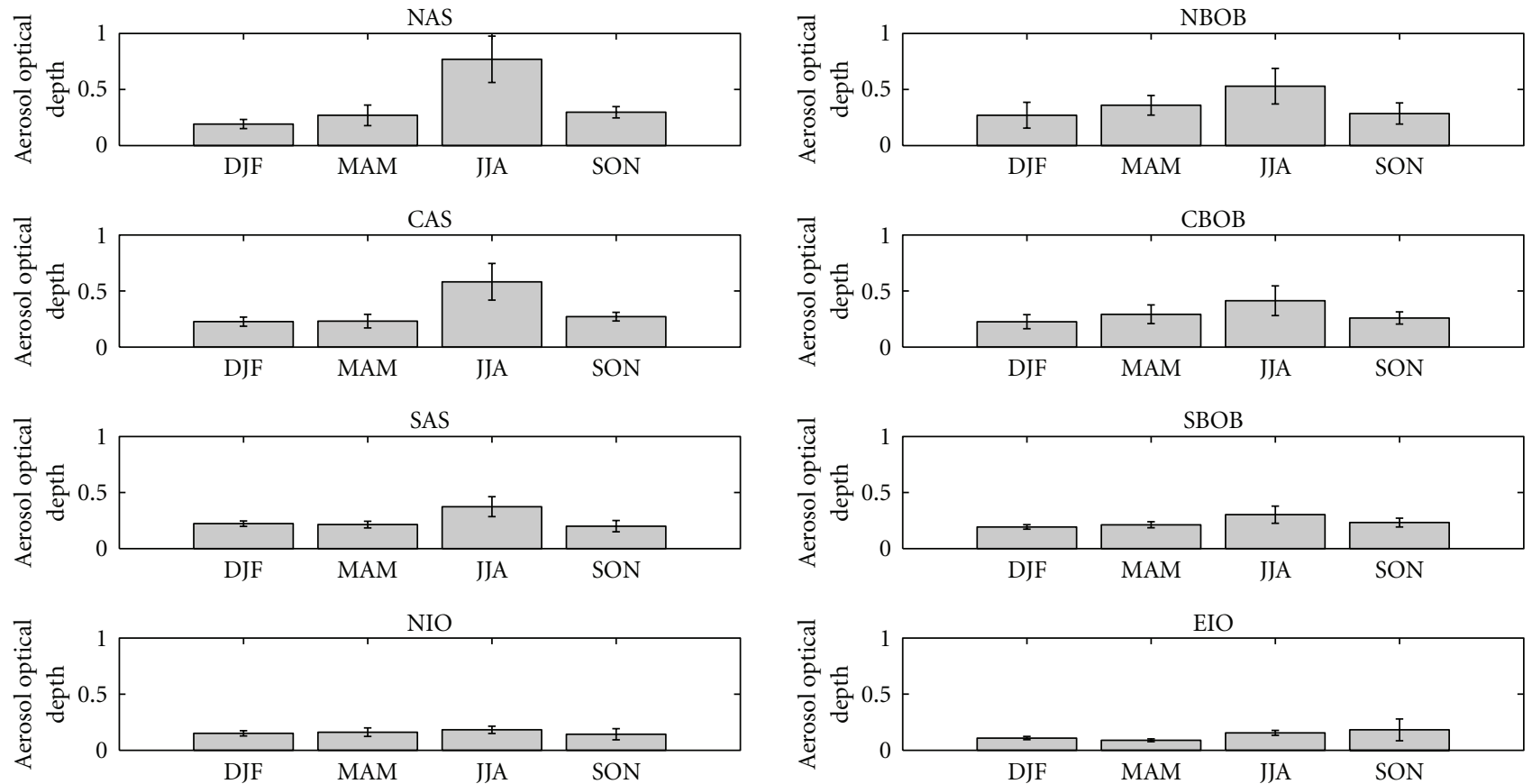

FIGURE 10: Average AOD for each sub-region region. The abbreviation over each sub-panel specifies the region.
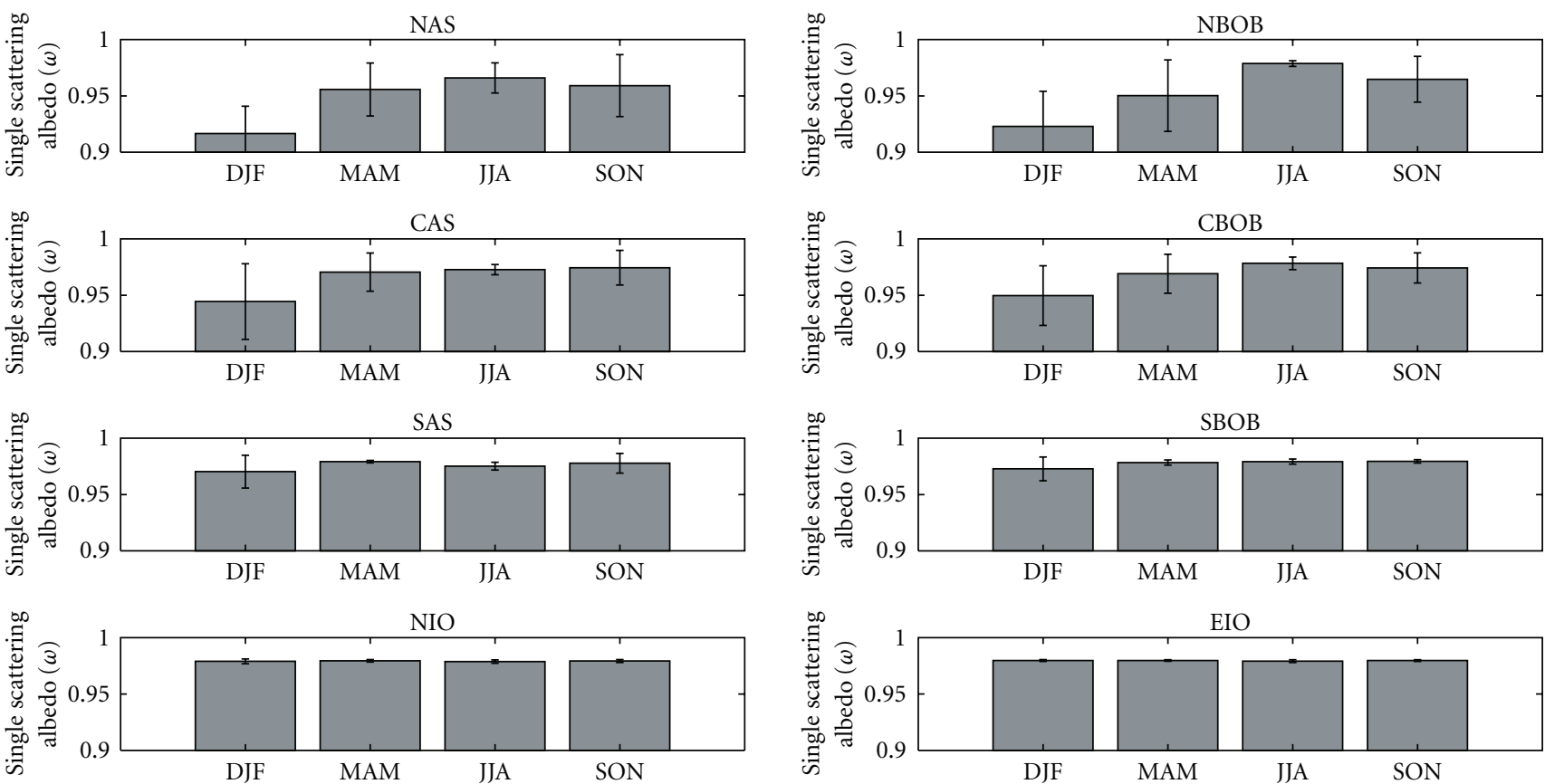

FIGURE 11: Mean single scattering albedo for each sub-region region.

period (1999) was larger compared to both 1998 and 2000. The present study, based on all season measurements made during 2006 at island location in Arabian Sea, has shown that the measured BC mass fraction were much lower than those observed in 1999. The annual mean aerosol radiative forcing estimated for the whole oceanic regions around India was -12 and $-7 \mathrm{~W} \mathrm{~m}^{-2}$ at surface and TOA, respectively.

\section{Summary and Conclusions}

We have retrieved regional distribution of aerosol column single scattering albedo using data from Ozone Monitoring Instrument (OMI) and Moderate Resolution Imaging Spectroradiometer (MODIS) instruments. Consequently, we provided improved assessment of short wave aerosol radiative forcing (ARF) (on both regional and seasonal scales) 

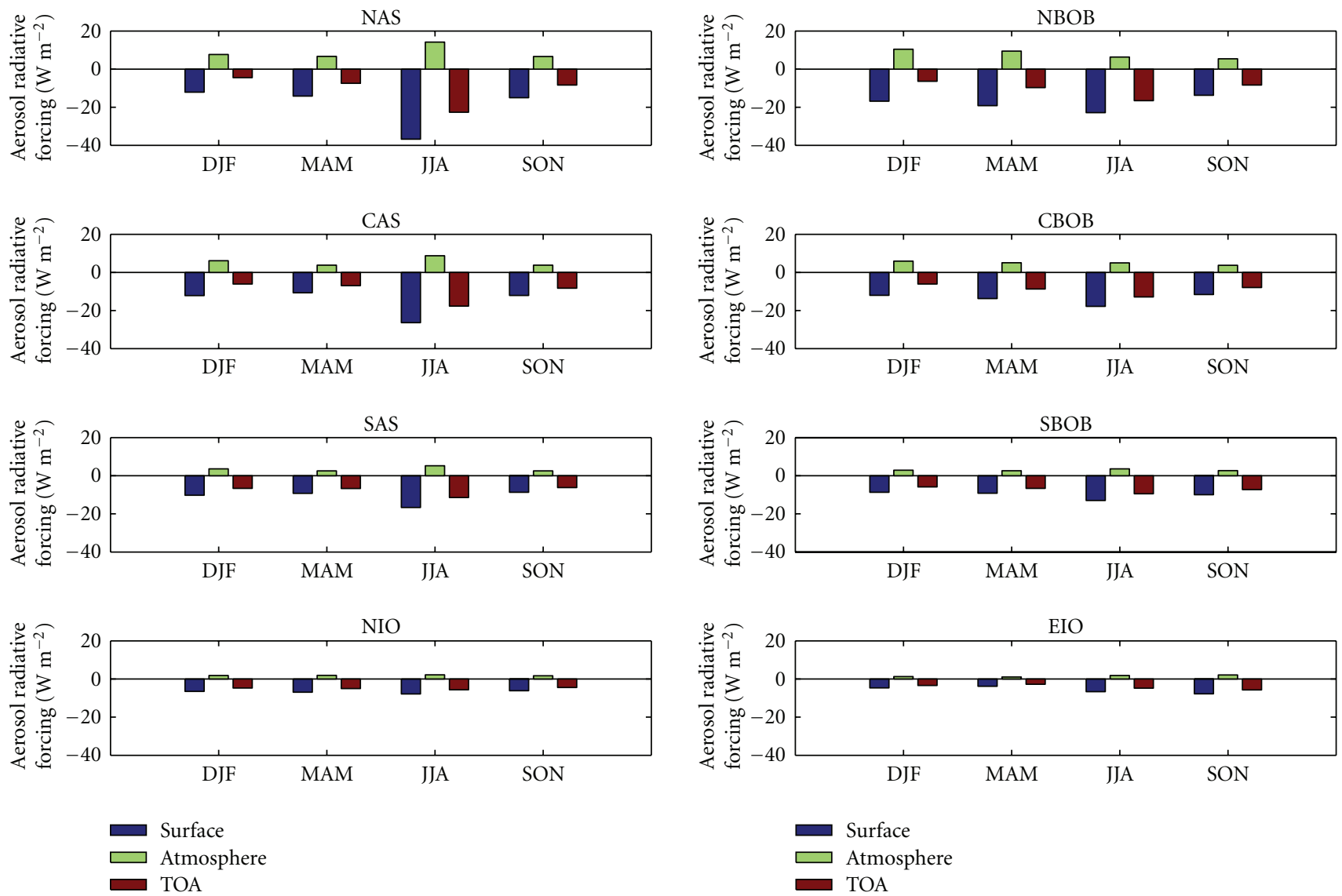

FIgURE 12: Mean aerosol radiative forcing for each sub-region region. The abbreviation over each subpanel specifies the region.

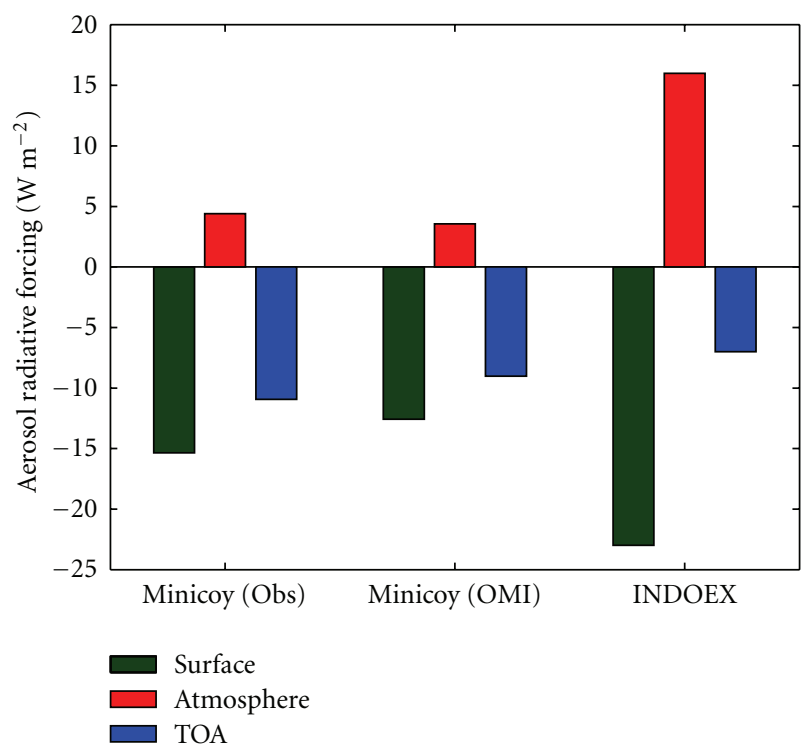

FIGURE 13: Comparison between the aerosol radiative forcing estimated at Minicoy from ground-based observation, satellite, and INDOEX.

estimates over this region. Major conclusions are listed as follows. (a) Large gradients in north-south ARF were observed as a consequence of gradients in single scattering albedo and aerosol optical depth.

(b) The highest ARF ( $-37 \mathrm{~W} \mathrm{~m}^{-2}$ at the Earth's surface) was observed over the northern Arabian Sea during June to August period (JJA).

(c) In general, ARF was higher over northern Bay of Bengal (NBoB) during winter and pre-monsoon period, whereas the ARF was higher over northern Arabian Sea (NAS) during the monsoon and postmonsoon period.

(d) The largest forcing observed over NAS during JJA is the consequence of large amounts of desert dust transported from the west Asian dust sources.

(e) High as well as seasonally invariant aerosol single scattering albedos $(\sim 0.98)$ were observed over the southern Indian Ocean region far from continents.

(f) The ARF estimates based on direct measurements made at a remote island location, Minicoy $\left(8.3^{\circ} \mathrm{N}\right.$, $73^{\circ} \mathrm{E}$ ) in the southern Arabian Sea are in good agreement with the estimates made following multisatellite analysis. 


\section{Acknowledgment}

One of the authors (S. K. Satheesh) would like to thank Department of Science and Technology (DST), New Delhi for the Swarna Jayanti Fellowship.

\section{References}

[1] P. Forster, V. Ramaswamy, P. Artaxo et al., "Changes in atmospheric constituents and in radiative forcing," in Climate Change 2007: The Physical Science Basis-Contribution of Working Group I to the Fourth Assessment Report of the Intergovernmental Panel on Climate Change, S. Solomon, D. Qin, M. Manning et al., Eds., chapter 2, pp. 130-234, Cambridge University Press, New York, NY, USA, 2007.

[2] L. A. Remer, D. Tanré, Y. J. Kaufman et al., "Validation of MODIS aerosol retrieval over ocean," Geophysical Research Letters, vol. 29, no. 12, pp. 1-4, 2002.

[3] Z. Li, X. Zhao, R. Kahn et al., "Uncertainties in satellite remote sensing of aerosols and impact on monitoring its long-term trend: a review and perspective," Annales Geophysicae, vol. 27, no. 7, pp. 2755-2770, 2009.

[4] J. T. Houghton, Y. Ding, D. J. Griggs et al., Eds., Climate Change 2001: The Scientific Basis, Contribution of Working Group I to the Third Assessment Report of the Intergovernmental Panel on Climate Change, Cambridge University Press, New York, NY, USA, 2001.

[5] J. Hansen, M. Sato, and R. Ruedy, "Radiative forcing and climate response," Journal of Geophysical Research D, vol. 102, no. 6, pp. 6831-6864, 1997.

[6] P. Chylek, G. Videen, D. Ngo, R. G. Pinnick, and J. D. Klett, "Effect of black carbon on the optical properties and climate forcing of sulfate aerosols," Journal of Geophysical Research, vol. 100, no. 8, pp. 16,325-16,332, 1995.

[7] J. M. Haywood and K. P. Shine, "The effect of anthropogenic sulfate and soot aerosol on the clear sky planetary radiation budget," Geophysical Research Letters, vol. 22, no. 5, pp. 603 606, 1995.

[8] J. E. Penner, C. C. Chuang, and K. Grant, "Climate forcing by carbonaceous and sulfate aerosols," Climate Dynamics, vol. 14, no. 12 , pp. 839-851, 1998.

[9] A. S. Ackerman, O. B. Toon, D. E. Stevens, A. J. Heymsfield, V. Ramanathan, and E. J. Welton, "Reduction of tropical cloudiness by soot," Science, vol. 288, no. 5468, pp. 1042-1047, 2000.

[10] V. Ramanathan, P. J. Crutzen, J. Lelieveld et al., "Indian Ocean Experiment: an integrated analysis of the climate forcing and effects of the great Indo-Asian haze," Journal of Geophysical Research D, vol. 106, no. 22, pp. 28371-28398, 2001.

[11] O. Torres, A. Tanskanen, B. Veihelmann et al., "Aerosols and surface UV products form Ozone Monitoring Instrument observations: an overview," Journal of Geophysical Research D, vol. 112, no. 24, Article ID D24S47, 2007.

[12] S. K. Satheesh, O. Torres, L. A. Remer et al., "Improved assessment of aerosol absorption using OMI-MODIS joint retrieval," Journal of Geophysical Research D, vol. 114, no. 5, Article ID D05209, 2009.

[13] V. Vinoj, S. S. Babu, S. K. Satheesh, K. K. Moorthy, and Y. J. Kaufman, "Radiative forcing by aerosols over the Bay of Bengal region derived from shipborne, island-based, and satellite (Moderate-Resolution Imaging Spectroradiometer) observations," Journal of Geophysical Research D, vol. 109, no. 5, Article ID D05203, 11 pages, 2004.
[14] V. Vinoj, A. Anjan, M. Sudhakar, S. K. Satheesh, J. Srinivasan, and K. K. Moorthy, "Latitudinal variation of aerosol optical depths from Northern Arabian Sea to Antarctica," Geophysical Research Letters, vol. 34, no. 10, Article ID L10807, 2007.

[15] D. Tanré, M. Herman, and Y. J. Kaufman, "Information on aerosol size distribution contained in solar reflected spectral radiances," Journal of Geophysical Research D, vol. 101, no. 14, pp. 19043-19060, 1996.

[16] D. Tanré, Y. J. Kaufman, M. Herman, and S. Mattoo, "Remote sensing of aerosol properties over oceans using the MODIS/EOS spectral radiances," Journal of Geophysical Research D, vol. 102, no. 14, pp. 16971-16988, 1997.

[17] R. C. Levy, L. A. Remer, D. Tanré et al., "Evaluation of the moderate-resolution imaging spectroradiometer (MODIS) retrievals of dust aerosol over the ocean during PRIDE," Journal of Geophysical Research D, vol. 108, no. 19, Article ID 8594, 13 pages, 2003.

[18] L. A. Remer, Y. J. Kaufman, D. Tanré et al., "The MODIS aerosol algorithm, products, and validation," Journal of the Atmospheric Sciences, vol. 62, no. 4, pp. 947-973, 2005.

[19] O. Torres, P. K. Bhartia, J. R. Herman, Z. Ahmad, and J. Gleason, "Derivation of aerosol properties from satellite measurements of backscattered ultraviolet radiation: theoretical basis," Journal of Geophysical Research D, vol. 103, no. 14, pp. 17099-17110, 1998.

[20] P. B. Russell, P. V. Hobbs, and L. L. Stowe, "Aerosol properties and radiative effects in the United States East Coast haze plume: an overview of the tropospheric aerosol radiative forcing observational experiment (TARFOX)," Journal of Geophysical Research D, vol. 104, no. 2, pp. 2213-2222, 1999.

[21] P. Hignett, J. P. Taylor, P. N. Francis, and M. D. Glew, "Comparison of observed and modeled direct aerosol forcing during TARFOX," Journal of Geophysical Research D, vol. 104, no. 2, pp. 2279-2287, 1999.

[22] O. Dubovik, B. N. Holben, Y. J. Kaufman et al., "Singlescattering albedo of smoke retrieved from the sky radiance and solar transmittance measured from ground," Journal of Geophysical Research D, vol. 103, no. 24, pp. 31903-31923, 1998.

[23] J. Qiu, L. Yang, and X. Zhang, "Characteristics of the imaginary part and single-scattering albedo of urban aerosols in northern China," Tellus Series B, vol. 56, no. 3, pp. 276-284, 2004.

[24] K. H. Lee, Z. Li, M. S. Wong et al., "Aerosol single scattering albedo estimated across China from a combination of ground and satellite measurements," Journal of Geophysical Research D, vol. 112, no. 22, Article ID D22S15, 2007.

[25] F. Zhao and Z. Li, "Estimation of aerosol single scattering albedo from solar direct spectral radiance and total broadband irradiances measured in China," Journal of Geophysical Research D, vol. 112, no. 22, Article ID D22S03, 2007.

[26] D. Ganguly, H. Gadhavi, A. Jayaraman, T. A. Rajesh, and A. Misra, "Single scattering albedo of aerosols over the central India: implications for the regional aerosol radiative forcing," Geophysical Research Letters, vol. 32, no. 18, Article ID L18803, 4 pages, 2005.

[27] B. N. Duncan, R. V. Martin, A. C. Staudt, R. Yevich, and J. A. Logan, "Interannual and seasonal variability of biomass burning emissions constrained by satellite observations," Journal of Geophysical Research D, vol. 108, no. 2, Article ID 4100, 22 pages, 2003.

[28] S. Menon, J. Hansen, L. Nazarenko, and Y. Luo, "Climate effects of black carbon aerosols in China and India," Science, vol. 297, no. 5590, pp. 2250-2253, 2002. 
[29] D. G. Streets, T. C. Bond, G. R. Carmichael et al., "An inventory of gaseous and primary aerosol emissions in Asia in the year 2000," Journal of Geophysical Research D, vol. 108, no. 21, pp. 30-23, 2003.

[30] S. K. Satheesh, K. K. Moorthy, Y. J. Kaufman, and T. Takemura, "Aerosol optical depth, physical properties and radiative forcing over the Arabian Sea," Meteorology and Atmospheric Physics, vol. 91, no. 1-4, pp. 45-62, 2006.

[31] V. S. Nair, S. S. Babu, and K. K. Moorthy, "Aerosol characteristics in the marine atmospheric boundary layer over the bay of bengal and arabian sea during ICARB: spatial distribution and latitudinal and longitudinal gradients," Journal of Geophysical Research D, vol. 113, no. 15, Article ID D15208, 2008.

[32] P. Ricchiazzi, S. Yang, C. Gautier, and D. Sowle, "SBDART: a research and teaching software tool for plane-parallel radiative transfer in the earth's atmosphere," Bulletin of the American Meteorological Society, vol. 79, no. 10, pp. 2101-2114, 1998.

[33] M. Hess, P. Koepke, and I. Schult, "Optical properties of aerosols and clouds: the software package OPAC," Bulletin of the American Meteorological Society, vol. 79, no. 5, pp. 831844, 1998.

[34] V. Vinoj, S. K. Satheesh, and K. K. Moorthy, "Optical, radiative, and source characteristics of aerosols at Minicoy, a remote island in the southern Arabian Sea," Journal of Geophysical Research D, vol. 115, no. 1, Article ID D01201, 2010. 

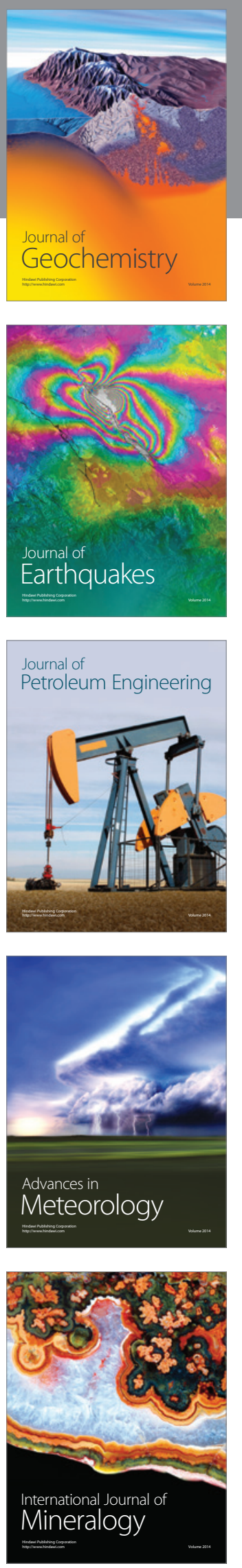
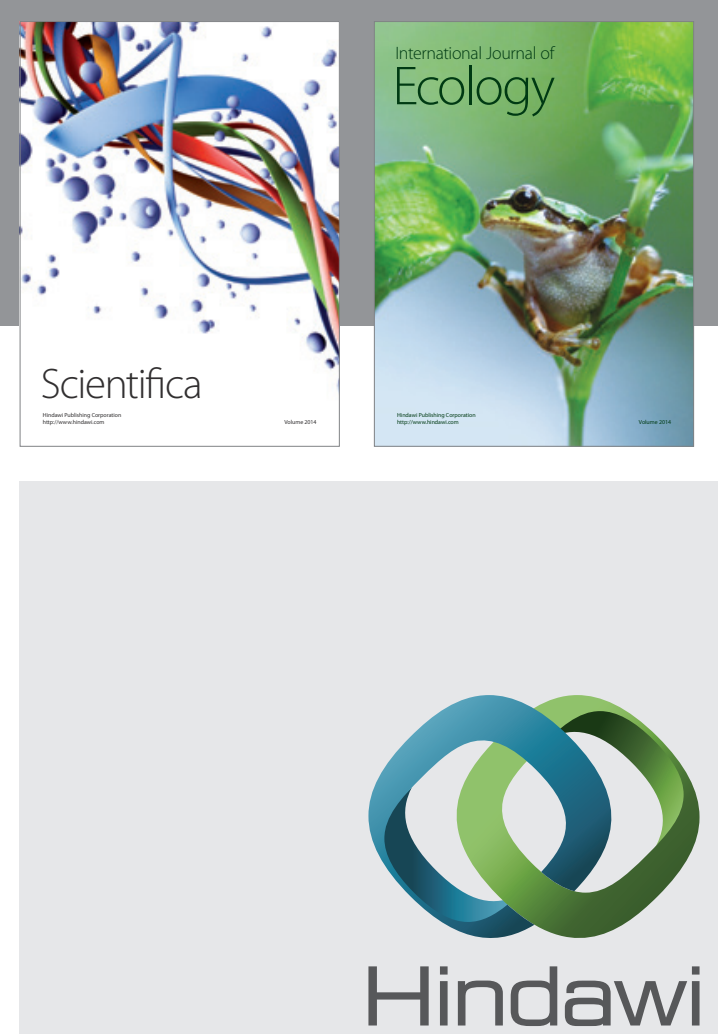

Submit your manuscripts at http://www.hindawi.com
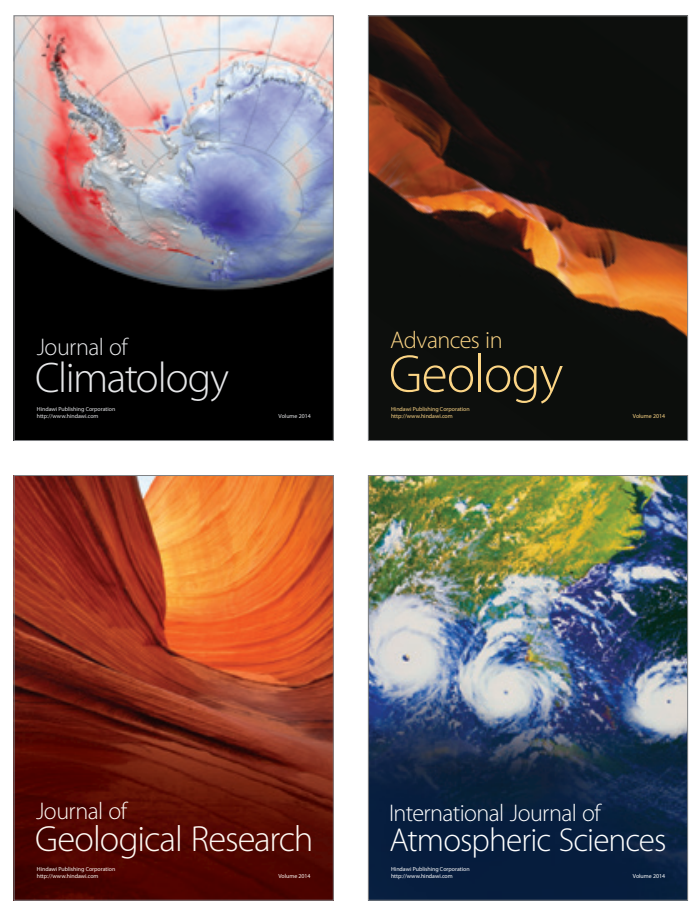
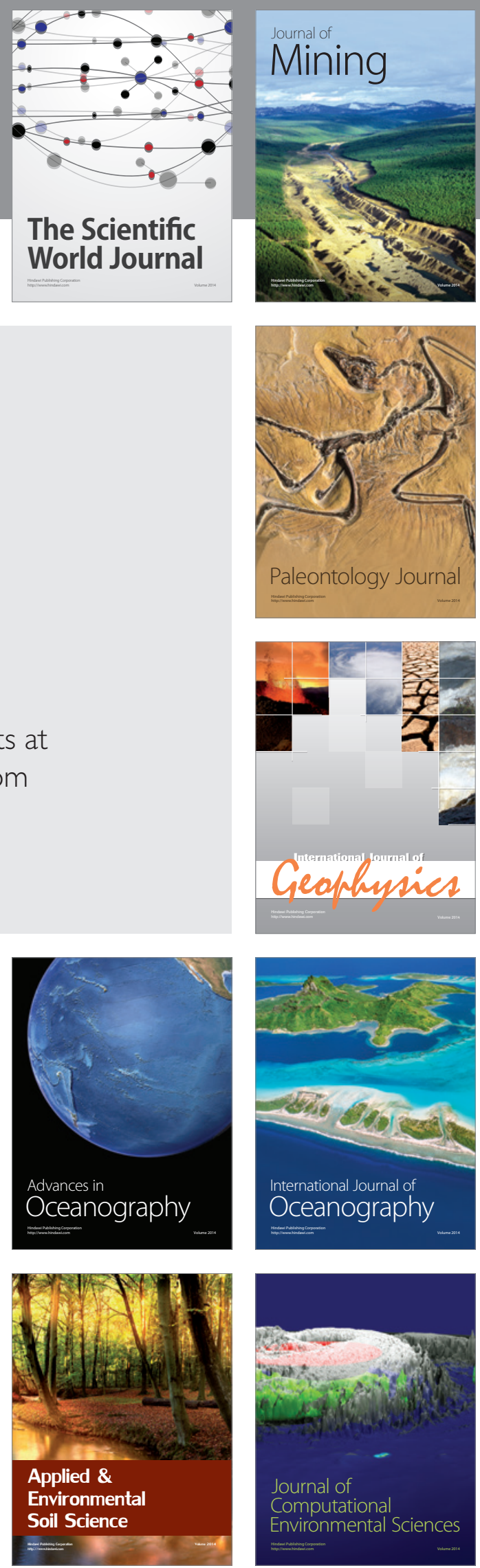